\title{
Oculodentodigital dysplasia
}

INSERM

\section{Source}

INSERM. (1999). Orphanet: an online rare disease and orphan drug data base.

Oculodentodigital dysplasia. ORPHA:2710

Oculodentodigital dysplasia (ODDD) is characterized by craniofacial, neurologic, limb and ocular abnormalities. 